\title{
WELFARE COST OF INFLATION IN BRAZIL: AN APPROACH WITH TIME-VARYING COINTEGRATION AND KALMAN FILTER ${ }^{\star}$
}

\author{
Eduardo Lima Campos ${ }^{\dagger}$ \\ Rubens Penha Cysne $\ddagger$
}

\begin{abstract}
This paper compares the time-varying cointegration and the Kalman filter techniques to estimate the Brazilian money demand between 1996 and 2015. The estimation using Kalman filtering performs better and is subsequently used to calculate the welfare cost of inflation. Taking into consideration the time variability of the interest-rate elasticity during the period, the average welfare cost amounts to $0.24 \%$ of the GDP, for an average annual inflation of $6.63 \%$.
\end{abstract}

Keywords: welfare cost of inflation, money demand, cointegration, Kalman filter.

\section{Resumo}

Este artigo compara as técnicas do filtro de Kalman e de cointegração variante no tempo para estimar a demanda brasileira por moeda entre 1996 e 2015. A estimação com o filtro de Kalman apresenta resultados melhores e é usada para calcular o custo de bem-estar da inflação. Considerando-se a variabilidade no tempo da elasticidade-juros durante o período, o custo médio de bem-estar foi estimado em $0,24 \%$ do PIB, para uma inflação anual média de 6,63\%.

Palavras-chave: custo de bem-estar da inflação, demanda por moeda, cointegração, filtro de Kalman.

JEL classification: E31, E41, I30

DOI: http://dx.doi.org/10.11606/1980-5330/ea141132

\footnotetext{
* This study was financed in part by the Coordenação de Aperfeiçoamento de Pessoal de Nível Superior - Brasil (CAPES) - Finance Code 001.

† Professor at FGV/EPGE and ENCE/IBGE. E-mail: eduardolimacampos@yahoo.com.br

‡ Professor at FGV/EPGE. E-mail: rubens.cysne@fgv.br
} 


\section{Introduction ${ }^{1}$}

The welfare or social cost associated with inflation can be defined as the potential loss to society, expressed as a percentage of its income, due to a certain positive inflation rate, taking as a reference a scenario of price stability. In his seminal approach to determine this cost, Bailey (1956) uses the microeconomic concept of consumer surplus, whereby money is the good and the nominal interest rate is the price.

The social impact of inflation is a result of the money demand's sensitivity to interest rates. This is measured by an elasticity, in the case of the logarithmic specification (Meltzer 1963b), or by a semi-elasticity, in the case of the semi-logarithmic specification (Cagan 1956). The choice of the best suitable specification and the estimation of the corresponding parameter are necessary to get the welfare cost of inflation.

Though Bailey's analysis uses a partial-equilibrium framework, Penha Cysne (2009) subsequently showed that Bailey's exact formula can be obtained through a Sidrauski (1967) general-equilibrium framework, under the assumption of quasilinear preferences. The advantage of this approach is that it allows for an endogenous determination of money demand, departing from first principles (preferences and technology).

Lucas Jr. (2000) uses empirical criteria to quantify Bailey's approach by applying it to the U.S. economy, using annual data from 1900 to 1994 . By adopting the logarithmic specification, he arrives at an estimated cost of approximately $1 \%$ of income for inflation of around $10 \%$ per year. Ireland (2009), using quarterly data for the U.S. economy (1979-2004), applies unit root tests and cointegration, obtaining a cost of $0.25 \%$ of income for the same annual rate of inflation, which is below the value obtained by Lucas. The author also suggests that the semi-logarithmic specification for money demand is more appropriate for this period. Serletis \& Yavari (2004) uses other econometric techniques to estimate the cost of inflation, obtaining results close to those of Ireland.

These works, as well as several others involving the welfare cost of inflation, consider the interest rate elasticities or semi-elasticities of the demand for money to be time invariant. Nevertheless, this strong hypothesis may not be supported by the available data.

Regarding time-varying methods, Hall et al. (1997), and Hansen (2003) provide methods that allow for transitions in the cointegration vectors between systems. However, these transitions occur abruptly. Choi \& Saikkonen (2004) present a method that allows for a smoother state transition of the cointegration vector. Lütkepohl et al. (1999) and Teräsvirta \& Eliasson (2001) consider time-varying money demand functions. These authors use single-equation error correction models.

Park \& Hanh (1999) proposed a method that allows for a smooth evolution of the cointegration vector over time, but this method has limited applicability since it considers only a single cointegration relationship between variables. Zuo \& Park (2011) apply this method to estimate the demand for money in the Chinese economy.

Bierens \& Martins (2010) present a more general and robust method of time-varying cointegration, which admits the possibility of multiple cointe-

\footnotetext{
${ }^{1}$ The authors thank Gabriel Novais for his research assistance.
} 
gration relationships. Miller et al. (2014) apply this method to quarterly data from the U.S. economy between 1959 and 2010. They consider the estimated elasticities to calculate the welfare cost of inflation, reaching a cost of $0.27 \%$ of income for an annual inflation rate of $10 \%$, a figure close to that obtained by Ireland (2009). However, they conclude that Lucas' specification (Lucas Jr. 2000) of the money demand function is more appropriate for the whole period, where the elasticity, and not the form of the function, is what should vary over time. This could explain the discrepancy between the results obtained by Lucas and those of Ireland. Barigozzi \& Conti (2014) apply this method to estimate the time-varying demand for money of the European economy.

Kumar (2014) specifies a more general money demand function using the Kalman filter to estimate the time-varying interest rate elasticity in the Indian economy for the period of 1996-2013. The author specifies the demand for money using a model employing a lagged dependent variable with the interest rate (or its logarithm) as a regression, and allowing for the elasticity or semielasticity to vary according to a random walk. He concludes that the semilogarithmic specification is best suited to the Indian economy and, from the estimated semi-elasticities, get the welfare cost of inflation for India.

In the case of the Brazilian economy, with regard to the estimation of demand for money, we highlight Canêdo-Pinheiro (2011) for the annual data from 1970 to 1994 . Concerning the welfare cost of inflation for the period after "Plano Real" in 1994, Caetano et al. (2014) estimate elasticities for quarterly data for the period from 1995 to 2011 using the methods of static and dynamic least squares. The authors arrive at an average cost between $0.3 \%$ and $0.45 \%$ of income for an annual inflation rate of $10 \%$; and between $0.15 \%$ and $0.2 \%$ for an annual inflation rate of $4.5 \%$.

This paper estimates the money demand function and evaluates the welfare cost of inflation, regarding the Brazilian economy, using monthly data between 1996 and 2015. The calculations use the approach proposed by Bailey (1956), implicitly assuming the general-equilibrium framework proposed by Penha Cysne (2009).

We allow for the parameters of the money demand function, and hence the costs of inflation, to vary throughout the period. Two methods are applied and compared to estimate a time-varying money demand function for the Brazilian economy. The first is the time-varying cointegration proposed by Bierens \& Martins (2010), which Miller et al. (2014) applied to the U.S. economy and Barigozzi \& Conti (2014) applied to the European economy. The second is the Kalman filter (Kalman 1960, Kalman \& Bucy 1961), also applied by Kumar (2014) to the Indian economy. Finally, regarding this work's contribution, it is worth mentioning that none of these methods were previously applied to calculate the welfare cost of inflation for Brazil.

\section{Overview of the Brazilian monetary experience: 1996-2016}

Figure 1 presents the evolution of the Selic interest rate, inflation (12-month cumulated series of the Comprehensive Consumer Price Index (IPCA)) and the money to GDP ratio between 1996 and 2015.

It is possible to verify that the money to GDP ratio tends to decrease as both inflation and interest rate increase. Besides that, as an example of the behavior of the money to GDP ratio, this figure shows important facts. The 
Figure 1: Inflation, Interest Rate and Money to GDP time series

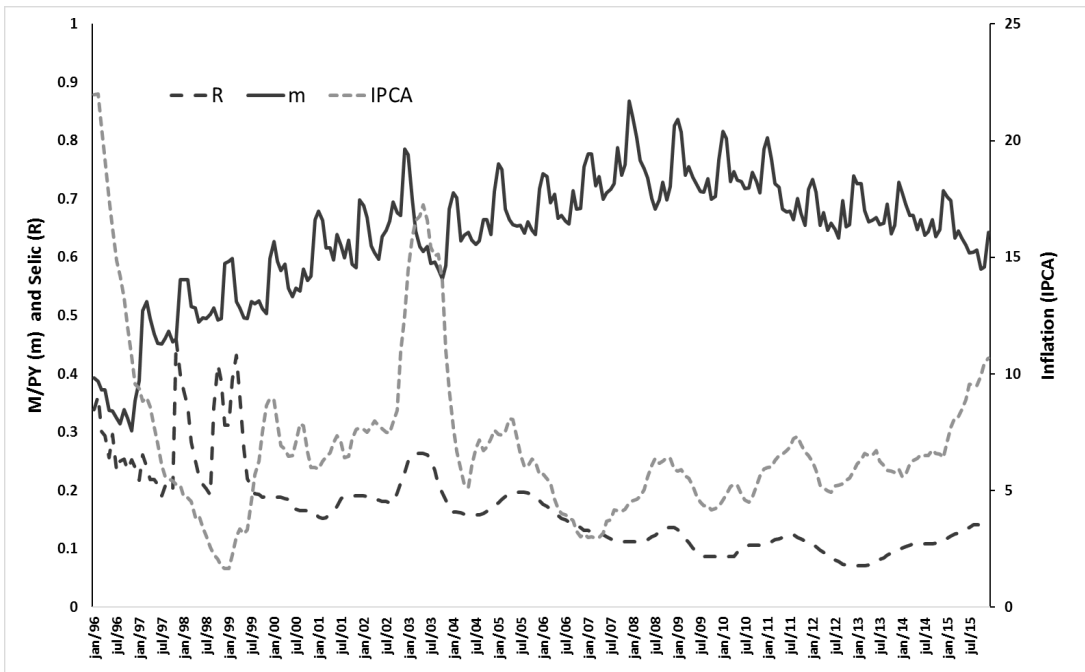

first is the constant fall of inflation and interest rates prior the 1998 crisis, due to the economic policy during Fernando Henrique Cardoso's first term. The others are the sudden rise prior to 2003, the U-turn of the Selic rate in the last year of Dilma's first term, and the inflation rate acceleration in 2015.

The interest elasticity represents the sensitivity of interest rate changes in the demand for money. Given the context of Brazilian monetary history, it is interesting to vary this elasticity in time due to intrinsic short-term events throughout the study period. The changes in the money to GDP ratio can't be justified by a constant elasticity of the interest rate, since it fluctuates very differently. The changing pattern of oscillations from January 2005 confirms this. The figure above shows these oddly variations in the interest rate and inflation series. Thus, the model incorporates important information on monetary policy under the varying elasticity hypothesis better than under the usual constant interest rate elasticity form.

\section{Methodology}

\subsection{Economic Models}

The welfare cost of inflation involves the money demand function. If $M$ is the money demand, $P$ is the price index, $Y$ is the nominal income/GDP, $y$ is the real income $(=Y / P)$, and $r$ is the nominal interest rate, the usual demand for money functions are either semi-logarithmic (Cagan 1956):

$$
\frac{M}{P}=k y^{\gamma} e^{-\xi r}
$$

or logarithmic (Meltzer 1963a): 


$$
\frac{M}{P}=k y^{\gamma} r^{-\eta}
$$

In the approach considered here, the cost of welfare is expressed as a percentage of GDP. Therefore, in its calculation it is necessary for $\gamma$ in (1) and (2) to equal 1 . This hypothesis can be empirically investigated (see, for example, Penha Cysne \& Issler (1993). By imposing such a restriction, (1) and (2) can be re-specified in terms of a new quantity called money-income ratio, $m=M / Y$ :

$$
\begin{aligned}
& m(r)=B e^{-\xi r} \\
& m(r)=A r^{-\eta}
\end{aligned}
$$

The parameters $\eta$ and $\xi$ are, respectively, the absolute values of the elasticity and semi-elasticity of money demand with respect to the interest rate. These parameters can be used to calculate the cost of inflation. The choice between the two specifications follows empirical criteria. For example, Lucas Jr. (2000) presents charts with the data adjusted in accordance with the two functions, concluding that the specification in (4) is superior for the data in his work. He determines the constant A by imposing the estimated curve passes through the geometric mean of the data points. Kumar (2014) concludes that, for the Indian economy, the specification in (3) fits better. The difference between these functional forms is particularly important in the calculation of the welfare cost of inflation for small values of the interest rate.

In this paper, we chose the logarithmic specification because it provided a better fit for the data than the semi-logarithmic, considering both estimation techniques adopted. With $\Psi(m)$ standing for the money demand function and $w(r)$ for the welfare cost of inflation as a fraction of GDP:

$$
w(r)=\int_{m(r)}^{m(0)} \Psi(x) d x=\int_{0}^{r} m(x) d x-r m(r)
$$

where $r m(r)$ is the seigniorage revenue. Substituting (4) in (5) we have ${ }^{2}$ :

$$
w(r)=\int_{0}^{r} A \tau^{-\eta} d \tau-A r r^{-\eta}=A \frac{\eta}{1-\eta} r^{1-\eta}
$$

In order to get the cost of inflation, an interest rate of $r_{0}$ should be considered as a reference, which would correspond to zero inflation. This rate is the neutral interest rate. We use a neutral interest rate of $5 \%$. Thus, the welfare cost of an inflation rate of $\pi$ should be calculated as $w(\pi+0.05)-w(0.05)$, where $\pi$ is the inflation rate.

\footnotetext{
${ }^{2}$ For the semi-logarithmic specification in (3), we have $w(r)=\frac{B}{\xi}\left[1-(1+\xi r) e^{-\xi r}\right]$. See Penha Cysne (2009), page 457, for an alternative way to get the same expression.
} 


\subsection{Time-Varying Cointegration}

To be able to estimate the parameters of the money demand functions presented in section 3.1, one must first linearize them, taking the logarithm on both sides and then introducing error terms. In this case, equations (1) and (2) lead to:

$$
\begin{gathered}
\ln \left(\frac{M_{t}}{P_{t}}\right)=\ln B+\gamma \ln \left(\frac{Y_{t}}{P_{t}}\right)-\xi r_{t} \\
\ln \left(\frac{M_{t}}{P_{t}}\right)=\ln A+\gamma \ln \left(\frac{Y_{t}}{P_{t}}\right)-\eta \ln r_{t}
\end{gathered}
$$

In the case of no rejection of the hypothesis that the income elasticity $\gamma$ is equal to 1 , which is necessary to calculate the welfare cost of inflation, the estimable form of equations (7) and (8) are:

$$
\begin{gathered}
\ln \left(m_{t}\right)=\ln B-\xi r_{t} \\
\ln \left(m_{t}\right)=\ln A-\eta \ln r_{t}
\end{gathered}
$$

where $m_{t}=\frac{M_{t}}{P_{t}} \frac{P_{t}}{Y_{t}}=\frac{M_{t}}{Y_{t}}$. The above variables are non-stationary, and in this case, cointegration tests are necessary to perform econometric modeling. Johansen (1988) suggests a method based on estimating the following vector error correction model:

$$
\Delta Z_{t}=\mu+\Pi^{\prime} Z_{t-1}+\sum_{j=1}^{p-1} \Gamma_{j} \Delta Z_{t-j}+\varepsilon_{t}, t=1,2, \ldots, T,
$$

where $Z_{t}=\left(Z_{1 t}, Z_{2 t}, \ldots, Z_{k t}\right)$ is a vector $(k x 1)$ of observations for each series, at instant $\mathrm{t}, \mu$ is a vector $(k x 1)$ of intercepts, $\Gamma_{j}, j=1, \ldots, p$, are vectors $(k x 1)$ of coefficients of $\Delta Z_{t-j}$, and $\varepsilon_{t}$ is a vector $(k x 1)$ of errors, so that $\varepsilon_{t} \sim N(0, \Omega)$. The Johansen test is based on the rank of $\Pi$. If the hypothesis that this matrix has a rank $r$ is not rejected, it is concluded that there are $r$ cointegrating vectors, where $r<k$, and in this case one can write $\Pi^{\prime}=\alpha \beta^{\prime}$, where $\beta$ is a matrix $(k x r)$ whose columns are the cointegration vectors and $\alpha$ is the corresponding speed of adjustment coefficients matrix.

In this paper, we consider a cointegration relationship that can vary over time. Park \& Hanh (1999) presents a method in which the evolution of the cointegration vector elements is defined from a Fourier series expansion. This procedure applies only to the case in which there is only one cointegration relationship between the variables. Bierens \& Martins (2010) suggest a more general procedure that extends Johansen's method, allowing for the incorporation of multiple cointegration relationships, considering the model:

$$
\Delta Z_{t}=\mu+\Pi_{t}^{\prime} Z_{t-1}+\sum_{j=1}^{p-1} \Gamma_{j} \Delta Z_{t-j}+\varepsilon_{t}, t=1,2, \ldots, T,
$$

where the only difference regarding specification (11) is that the matrix $\Pi$ 
varies over time. Two aspects should be highlighted in (12): the vector of intercepts $\mu$ is time-invariant and $\Pi^{\prime}=\alpha \beta_{t}^{\prime}$, so that only $\beta$ varies over time with $\alpha$ kept constant. The evolution of $\beta$ over time is represented by Chebyshev polynomials, defined as follows: $P_{0}, T(t)=1, P_{i, T}(t)=2^{1 / 2} \cos (i \pi(t-0.5) / T), t=$ $1,2, \ldots, T-1$. It can be proven that any function $g(t)$ of time can be represented as a linear combination of $T-1$ Chebyshev polynomials (Hamming 1973).

Nevertheless, in practice one should choose (via statistical criteria) a number $\mathrm{m}$ of polynomials that satisfactorily approximates the trajectory of $\beta$ :

$$
\beta_{t}=\sum_{i=0}^{m} \xi_{i, T} P_{i, T}(t)
$$

For higher values of $m$, the approach becomes more accurate but less smooth. A low value of $m$ imposes smoother behavior on $\beta_{t}$, approaching the invariant case. Thus, a positive aspect of the method is the great flexibility to adjust to different standards of behavior in the cointegration vector over time, capturing possible nonlinear long-term relationships (see, e.g., Granger (1987)).

By substituting (13) in (12) and rewriting the model conveniently, we have:

$$
\Delta Z_{t}=\mu+\alpha \xi^{\prime} Z_{t-1}^{(m)}+\Gamma X_{t}+\varepsilon_{t}
$$

where $\xi^{\prime}=\left[\xi_{0}^{\prime}, \xi_{1}^{\prime}, \ldots, \xi_{m}^{\prime}\right]$ is a matrix $[r x(m+1) k]$, of rank $r, Z_{t-1}^{(m)}=$ $\left(Z_{t-1}^{\prime}, P_{1 T}(t) Z_{t-1}^{\prime}, P_{2, T}(t) Z_{t-1}^{\prime}, \ldots, P_{m, T}(t) Z_{t-1}^{\prime}\right)$ and $X_{t}=\left(\Delta Z_{t-1}^{\prime}, \ldots, \Delta Z_{t-p+1}^{\prime}\right)^{\prime}$. To check for evidence of time-varying cointegration, one must test the hypothesis $H_{0}: \Pi_{t}^{\prime}=\alpha \beta^{\prime}$ vs. $H_{1}: \Pi_{t}^{\prime}=\alpha \beta_{t}^{\prime}$. Under $H_{0}$ (restricted model), $\xi^{\prime}=\left(\beta^{\prime}, O_{r, k m}^{\prime}\right)$, where $\beta$ is a matrix $(k x r)$ whose columns are invariant cointegration vectors, so that in (14), $\xi_{Z_{t-1}^{(m)}}=\beta^{\prime} Z_{t-1}^{(0)}$, with $Z_{t-1}^{(0)}=Z_{t-1}^{\prime}$. Therefore, under $H_{0}$, the coefficients of terms referring to the Chebyshev polynomial in (14) get annulled with the exception of the first one, which corresponds to $m=0$, a case in which the cointegration is invariant. Moreover, $H_{1}$ postulates that at least some of the coefficients (14) are different from zero, and therefore, the series displays time-varying cointegration. To test these hypotheses, we adopted the wild bootstrap and sieve bootstrap methods, which attenuate distortions in the size of the likelihood-ratio test. Wild bootstrap comprises the following steps:

Step 1 - Generate B ( $B=5,000$ was used) to create a replica of pseudonoise sequences $\left\{\xi_{t}^{b}=\hat{\xi}_{t} \omega_{t}\right\}_{t=1}^{T}$, for $b=1,2, \ldots, B$, where $\left\{\hat{\xi}_{t}\right\}_{t=1}^{T}$ are residuals of the estimation of (14) and $\left\{\omega_{t}\right\}_{t=1}^{T}$ are independent realizations of random variables $N(0,1)$.

Step 2 - Use the pseudo-noise from step 1 to reconstruct the series generating bootstrap samples $\left\{\Delta Z_{t}^{b}\right\}_{t=1}^{T}$, where:

$$
\Delta Z_{t}^{b}=\hat{\mu}+\hat{\Pi}^{\prime} Z_{t-1}^{b}+\sum_{j=1}^{p-1} \hat{\Gamma}_{j} \Delta Z_{t-j}^{b}+\xi_{t}^{b}, t=1,2, \ldots, T,
$$

with initial values $Z_{t}^{b}=Z_{t}, t=-(p+1), \ldots, 0$. 
Step 3 - Use the bootstrap sample obtained in step 2 to calculate the likelihood-ratio statistic $L R^{C V}=T \sum_{j=1}^{r} \ln \left(\frac{1-\hat{\lambda}_{0 j}^{b}}{1-\hat{\lambda}_{m j}^{b}}\right)$, where $\hat{\lambda}_{0 j}^{b}$ are $\hat{\lambda}_{m j}^{b}$ the largest eigenvalues associated with $\hat{\Pi}^{\prime}$ under $H_{0}$ and $H_{1}$, respectively.

Step 4 - Consider the percentiles of the empirical distribution obtained via bootstrap as critical values for the test, hereinafter denominated empirical critical values. The sieve bootstrap consists of the same procedure, changing only step 1 , in which the pseudo-residuals are now generated by a simple random sample with replacement of $\left\{\hat{\xi}_{t}-\frac{1}{T} \sum_{t=1}^{T} \hat{\xi}_{t}\right\}_{t=1}^{T}$. For more details, see Martins (2018).

\subsection{Kalman Filtering}

The state-space representation (Harvey 1989) is a way of expressing a linear statistical model which allows the estimation of the parameters of this model for each instant of time. This representation consists of two equations. The first is the observation equation, which represents the evolution of $y_{t}$ over time:

$$
y_{t}=z_{t}^{\prime} \alpha_{t}+\varepsilon_{t}
$$

where $z_{t}$ is a vector $(m x 1), \alpha_{t}$ is a vector $(m x 1)$ called state vector, and $\varepsilon_{t}$ is a white noise term with zero mean and variance $\sigma_{\varepsilon}^{2}$, for $t=1,2, \ldots, T$, wherein $T$ is the total number of observations ${ }^{3}$.

The second equation is the state transition:

$$
\alpha_{t}=T_{t} \alpha_{t-1}+v_{t}
$$

where $T_{t}$ is a matrix $(m \times m)$, called state transition matrix and $v_{t}$ is a vector ( $g \times 1)$ of uncorrelated white noise terms, with zero mean and covariance matrix $Q_{t}$. The error terms $\varepsilon_{t}$ and $v_{t}$ satisfy $E\left(\varepsilon_{t} v_{s}^{\prime}\right)=0, \forall t, s=1,2, \ldots, T$. The state vector at instant $t=0, \alpha_{0}$, has mean $a_{0}$ and covariance matrix $P_{0}$, such that $E\left(\varepsilon_{t} \alpha_{0}^{\prime}\right)=0$ and $E\left(\kappa_{t} v_{0}^{\prime}\right)=0, \forall t=1,2, \ldots, T$.

We investigate four possibilities regarding the money demand. The first formulation is based on the estimable form with logarithmic specification in equation (4):

$$
\begin{gathered}
y_{t}=\mu+\eta_{t} x_{t}+\varepsilon_{t} \\
\eta_{t}=\eta_{t-1}+v_{t},
\end{gathered}
$$

where $\mu=\ln (A), y_{t}=\ln \left(m_{t}\right), x_{t}=\ln \left(r_{t}\right)$, and the elasticity $\eta_{t}$ follows a random walk. (3):

The second formulation, in turn, is based on the semi-logarithmic form in

$$
y_{t}=\mu^{*}+\xi_{t} x_{t}+\varepsilon_{t}
$$

\footnotetext{
${ }^{3}$ In order to simplify the exposition, we omitted some terms in state-space representation
} 


$$
\xi_{t}=\xi_{t-1}+v_{t}
$$

where $\mu *=\ln (B), x_{t}=r_{t}$, and the semi-elasticity $\xi_{t}$ follows a random walk.

The state-space representation of (18)-(19) in (the case of (20)-(21) is quite similar) is:

$$
\begin{gathered}
y_{t}=\left(\begin{array}{ll}
1 & x_{t}
\end{array}\right)\left(\begin{array}{c}
\mu_{t} \\
\eta_{t}
\end{array}\right)+\varepsilon_{t} \\
\left(\begin{array}{l}
\mu_{t} \\
\eta_{t}
\end{array}\right)=\left(\begin{array}{ll}
1 & 0 \\
0 & 1
\end{array}\right)\left(\begin{array}{l}
\mu_{t-1} \\
\eta_{t-1}
\end{array}\right)+\left(\begin{array}{c}
0 \\
v_{t}
\end{array}\right)
\end{gathered}
$$

that is, in (16)-(17), make $z_{t}^{\prime}=\left(\begin{array}{cc}1 & x_{t}\end{array}\right), \alpha_{t}=\left(\begin{array}{l}\mu_{t} \\ \eta_{t}\end{array}\right)$ and $T_{t}=\left(\begin{array}{ll}1 & 0 \\ 0 & 1\end{array}\right)$.

We show a more flexible specification for the money demand function below. It is possible to incorporate a lag of yt in equation (18), thus obtaining:

$$
\begin{gathered}
y_{t}=\mu+\phi y_{t-1}+\eta_{t} x_{t}+\varepsilon_{t} \\
\eta_{t}=\eta_{t-1}+v_{t},
\end{gathered}
$$

where $\varepsilon_{t}$ and $v_{t}$ are white noises, $y_{t}=\ln \left(m_{t}\right)$ and $x_{t}=\ln \left(r_{t}\right)$. We call that the extended specification. The state-space representation of the system in (24)-(25) is:

$$
\begin{aligned}
y_{t} & =\left(\begin{array}{lll}
1 & y_{t-1} & x_{t}
\end{array}\right)\left(\begin{array}{c}
\mu_{t} \\
\phi_{t} \\
\eta_{t}
\end{array}\right)+\varepsilon_{t} \\
\left(\begin{array}{c}
\mu_{t} \\
\phi_{t} \\
\eta_{t}
\end{array}\right) & =\left(\begin{array}{lll}
1 & 0 & 0 \\
0 & 1 & 0 \\
0 & 0 & 1
\end{array}\right)\left(\begin{array}{c}
\mu_{t-1} \\
\phi_{t-1} \\
\eta_{t-1}
\end{array}\right)+\left(\begin{array}{c}
0 \\
0 \\
v_{t}
\end{array}\right),
\end{aligned}
$$

that is, in (16)-(17), make $z_{t}=\left(\begin{array}{lll}1 & y_{t-1} & x_{t}\end{array}\right), \alpha_{t}=\left(\begin{array}{c}\mu_{t} \\ \phi_{t} \\ \eta_{t}\end{array}\right)$ and $T_{t}=$ $\left(\begin{array}{lll}1 & 0 & 0 \\ 0 & 1 & 0 \\ 0 & 0 & 1\end{array}\right)$

We estimate these equations by Kalman filter (Kalman 1960, Kalman \& Bucy 1961). This method consists of predictive and updating - or filtering - equations. The predictive equations represent the expected value and the variance of the state vector at time $t$, subject to the available observations up to $t-1$, denoted by $Y_{t-1}=\left\{y_{1}, y_{2}, \ldots, y_{t-1}\right\}$. Thus:

\footnotetext{
${ }^{4}$ The initial value of the state vector is $\alpha_{t}=\left(\begin{array}{c}\mu \\ \phi \\ 0\end{array}\right)$, thus maintaining consistency with equation (24).
} 


$$
\begin{gathered}
a_{t \mid t-1}=E\left(\alpha_{t} \mid Y_{t-1}\right)=T_{t} a_{t-1 \mid t-1} \\
P_{t \mid t-1}=V\left(\alpha_{t} \mid Y_{t-1}\right)=T_{t} P_{t-1 \mid t-1} T_{t}^{\prime}+Q_{t}^{\prime}
\end{gathered}
$$

The update - or filtering - equations represent the expected value and the variance of the state vector at $t$, subject to the available observations up to time $t, Y_{t}=\left\{y_{1}, y_{2}, \ldots, y_{t}\right\}$ :

$$
\begin{gathered}
a_{t \mid t}=E\left(\alpha_{t} \mid Y_{t}\right)=a_{t \mid t-1}+K_{t}\left(y_{t}-z_{t} a_{t \mid t-1}\right) \\
P_{t \mid t}=V\left(\alpha_{t} \mid Y_{t}\right)=P_{t \mid t-1}-K_{t} z_{t}^{\prime} P_{t \mid t-1}^{\prime}
\end{gathered}
$$

where the expression $K_{t}=P_{t \mid t-1} z_{t}^{\prime}\left(z_{t} P_{t \mid t-1} z_{t}^{\prime}-\sigma_{\varepsilon}^{2}\right)^{\prime}$ is called Kalman gain.

For the estimation of coefficients of the money demand function, we used smoothing equations, which consider the information of the whole sample to estimate the coefficients at each instant $t$, thus allowing a more efficient estimation. These equations are shown below:

$$
\begin{gathered}
a_{t \mid T}=E\left(\alpha_{t} \mid Y_{T}\right)=a_{t}+P_{t} T_{t}^{\prime} P_{t+1 \mid t}^{-1}\left(a_{t+1 \mid T}-T_{t} a_{t}\right) \\
P_{t \mid T}=V\left(\alpha_{t} \mid Y_{T}\right)=P_{t}+P_{t} T_{t}^{\prime} P_{t+1 \mid t}^{-1}\left(P_{t+1 \mid T}-P_{t}\right)\left[P_{t} T_{t}^{\prime} P_{t+1 \mid t}^{-1}\right]^{\prime}
\end{gathered}
$$

The variances of error terms, $\sigma_{\varepsilon}^{2}$, and the elements of $Q_{t}$, are fixed parameters (hyperparameters), estimated by the maximum likelihood method (Harvey 1989).

\section{Data}

We describe the variables used in this study below. Regarding the money demand, we use a monthly average of the daily values of the monetary aggregate M1. Under the assumption of an economy in which the only currency is the usual means of payment, consisting of paper money held by individuals plus demand deposits at commercial banks, $M 1$ can be considered to represent the demand for money.

For income, we consider the monthly nominal GDP at current values, available at Brazilian Central Bank's Time Series System. Since the nominal GDP is calculated quarterly by IBGE, the Central Bank obtains the monthly values by interpolation. The interest rate used is Selic, the benchmark rate for the Brazilian economy, accrued monthly and annualized. For inflation, we use the 12-month cumulative series of the Comprehensive Consumer Price Index $(\text { IPCA })^{5}$.

\footnotetext{
${ }^{5}$ Source of IPCA: http://www.ibge.gov.br. Source of M1, SELIC and GDP: http://www.bcb.gov.br.
} 


\section{Results and Comparison of Methods}

\subsection{Test for Unitary Income-Elasticity and Choice of Money Demand Function}

It is necessary to check the hypothesis that the income elasticity of money demand is equal to 1 . This hypothesis is essential for calculating the welfare cost of inflation. The procedure adopted here is based on Figure 2, the graph of the coefficient $\gamma_{t}$ of $\ln \left(y_{t}\right)$, obtained from the estimation of (7)-(8) by the time-varying cointegration method.

The confidence intervals were generated using the sieve bootstrap method. The null hypothesis that the income coefficient is equal to 1 will not be rejected if the number of times the confidence interval contains the value 1 is compatible with the likelihood of nominal coverage specified for the range.

Note that that most of the data points are situated within this range. Specifically, 222 of the 231 (approximately 96\%) generated intervals contain the value 1 , leading to the non-rejection of the hypothesis of unitary incomeelasticity over time, since the likelihood of nominal coverage for the interval is $95 \%$. The result with the semi-logarithmic specification was different: 24 intervals (more than 10\%) did not contain 1. Therefore, based on criteria in Bierens \& Martins (2010), we decided to adopt the logarithmic specification for the money demand function.

\subsection{Time-Varying Cointegration Results}

The estimation by time-varying cointegration was made with the software EasyReg $-2015^{6}$ version. Applying the method described in section 3.2, the hypothesis of time-varying cointegration was accepted at 0.05 significance level $(p$-value $=0.0392)$. The specification ( $p$ and $m$ values $)$ was selected by minimizing the information criteria available in the software (BIC and HQ), resulting in $p=11$ and $m=22$. Notwithstanding the fact that low values of $m$ represent smoother trajectories for the cointegration vector, and vice versa (Bierens \& Martins 2010), the elasticity estimates provided by the final model showed some instability, not only over time but also between concurrent specifications, for $m$ and $p$ values close to the ones selected by a sensitivity test.

Henceforth, we will refer to elasticities by their absolute value.

Figure 3 shows the estimate of interest-elasticity of demand for money, considering the logarithmic specification and the method of time-varying cointegration with the respective $95 \%$ confidence interval calculated by sieve bootstrap, as in Figure 2.

This method provides estimates with sharp fluctuations, varying between 0.2 and 0.48 . In particular, we draw attention to the fact that the oscillations of the elasticities series occur in amplitudes greater than those which characterize the evolution of interest rates and inflation in the period.

\subsection{Kalman Filter Results}

Figure 4 presents the interest-elasticity of demand for money over time estimated by the extended Kalman filter, thus considering the (24)-(25) specification for the state-space model. The smoothing equations (32)-(33) were

\footnotetext{
${ }^{6}$ http://personal.psu.edu/hxb11/ERIDOWNL.HTM
} 
Figure 2: Income-Elasticity Over Time - Logarithmic Specification

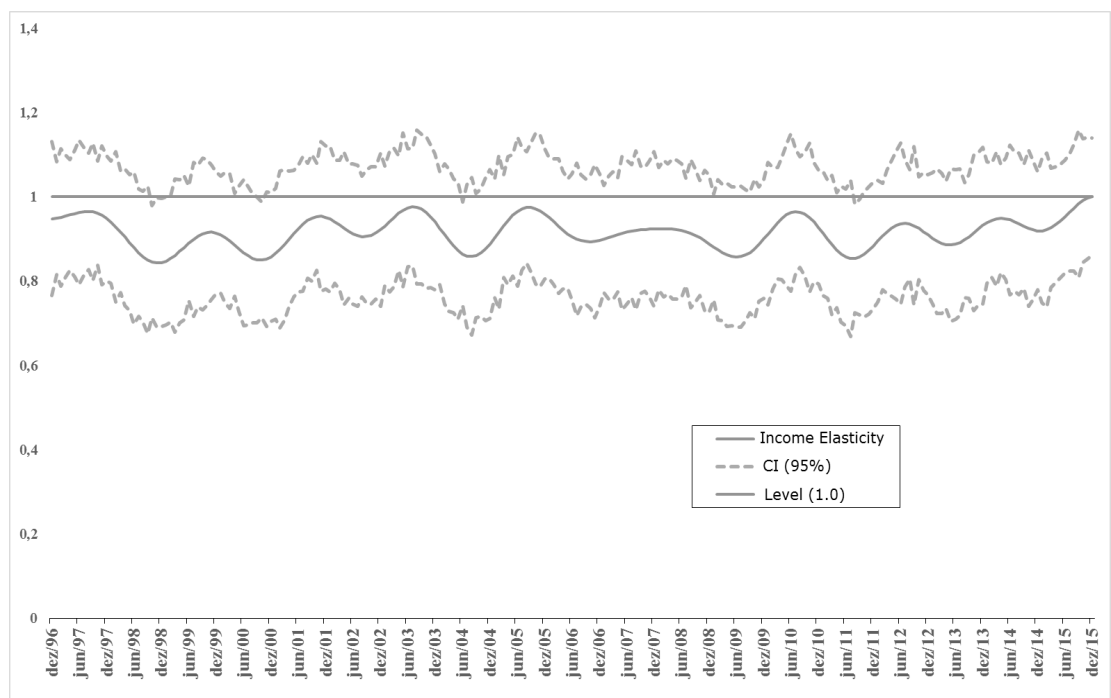

Figure 3: Interest-Elasticity of Demand for Money Estimated - Time-Varying Cointegration

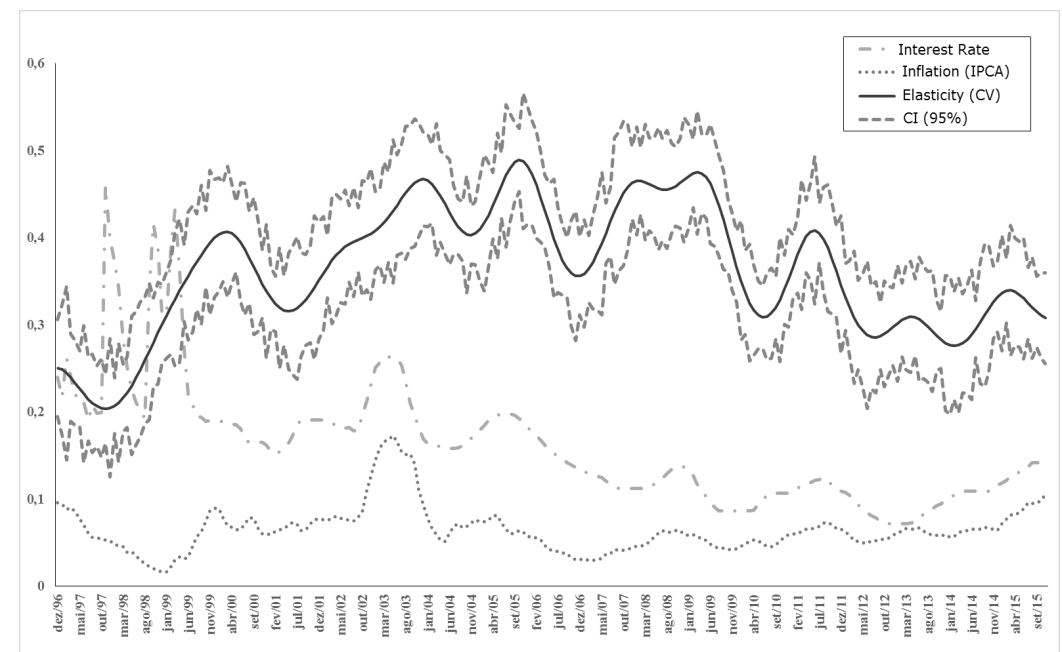


applied, since this enables a more appropriate comparison with the results provided by the time-varying cointegration method.

Figure 4: Interest-Elasticity of Demand for Money Estimated - Kalman Filter

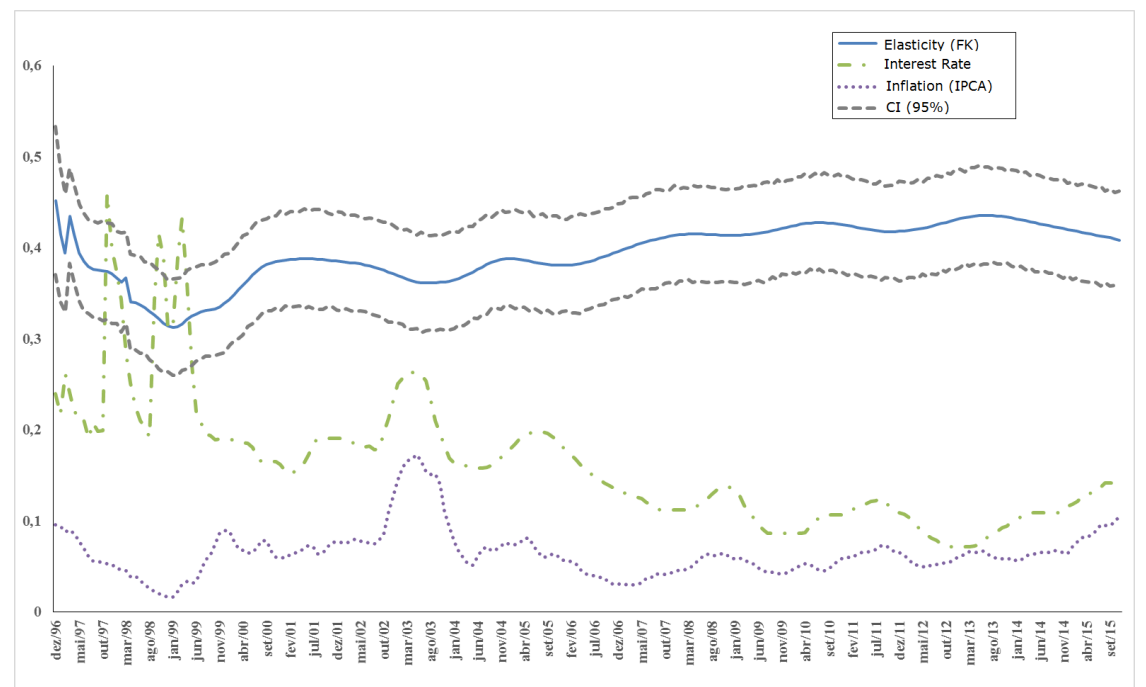

We can see that the Kalman filter provides more stable results than those in Figure 3. However, both of them have enough variability in the study period, showing that one should be cautious when considering this parameter constant over time. On the other hand, estimates provided by the Kalman filter, while oscillating around values close to those in the time-varying cointegration method, show greater stability. The fluctuation of elasticity series in Figure 4 features relatively smooth transitions and a more coherent evolution with the economic scenario, ranging between 0.32 and 0.45 . For comparison purposes, Caetano et al. (2014) arrive at an average elasticity between 0.42 and 0.51. However, they use quarterly data, a different period (1994-2011) and different estimation methods.

In particular, Figure 4 tends to show a negative correlation between interest rates and interest elasticity. It consists of an increased elasticity in response to the minimum point reached by the series of interest rates in mid2013, and then a decreasing tendency - following the path of the gradual rise in interest rates observed thereafter in the Brazilian economy - reaching a level slightly below 0.4 in late 2015. It is also worth noting that there was a drop (lagged) in elasticity for the period of high inflation in the transition period of 2002-2003.

Another advantage of Kalman filtering is that it allows for obtaining variance estimations directly from equation (33). These estimates were used to calculate the confidence intervals shown in Figure 4 , which are more stable than those in Figure 3. 


\subsection{Comparison Between Methods}

We compare the methods by creating graphs of the money demand function for three cases: the conventional (Lucas Jr. 2000), in which the constant A is determined so as to pass through the geometric mean of the data points and the elasticity is considered constant over time; time-varying cointegration; and Kalman filtering.

Figures 5 to 7 illustrate the estimated curves superimposed on the scatter plot of data points, allowing for the comparison of adjustments.

Figure 5: Time - Invariant (Conventional) Money Demand Function

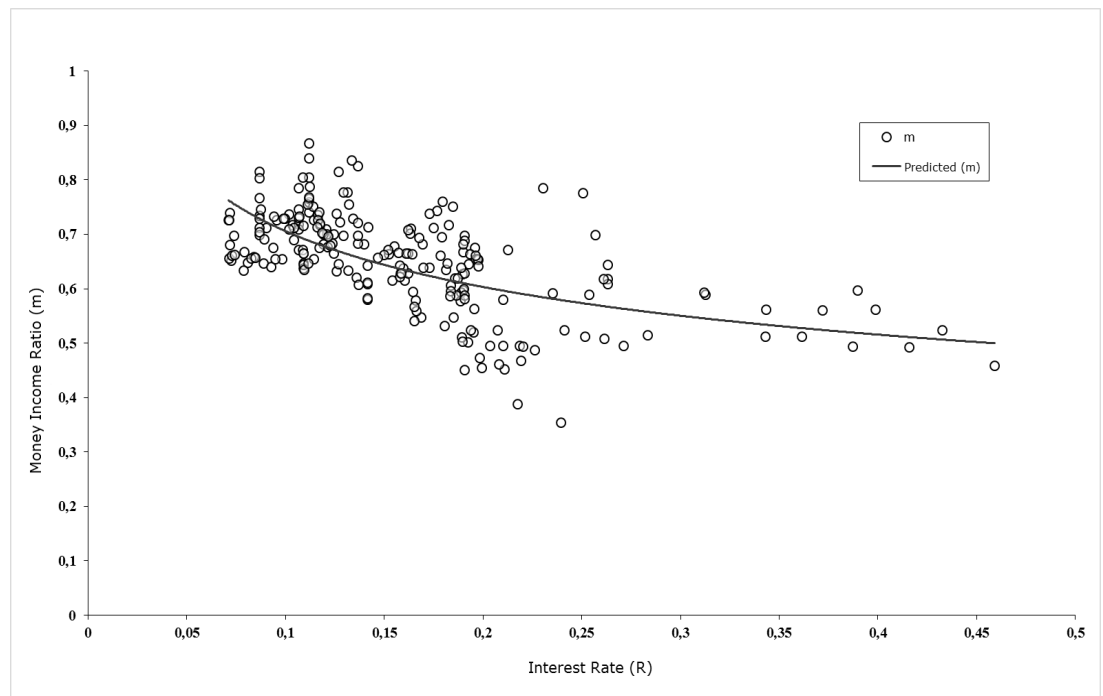

Note that both time-varying methods fits the points better than the conventional method, in particular to those distant from the curve in the conventional method. It is also possible to identify, by graphical inspection, a slight superiority of Kalman filtering. Figures 8 to 10 compares estimated and real demand for money for all methods.

It is clear, from Figures 8 to 10 , that the time variant methods allows much better fit to the data than the invariant method, over the study period. For a formal comparison, the following table compares the RMSE and the MAPE for estimated demand for money.

\section{Welfare Cost of Inflation}

In this section, we present the welfare cost of inflation using the estimates of interest-elasticity provided by the estimation via Kalman filtering of the extended specification of the money demand function. A neutral interest rate equal to $r_{0}=0.05$ is considered. The welfare cost is associated with inflation $\pi$ obtained by $w(\pi+0.05)-w(0.05)$, in which $w(r)$ is given by (6), where $\pi$ is the actual yearly inflation, month to month. Figure 11 illustrates the evolution 
Figure 6: Money Demand Function - Time-Varying Cointegration

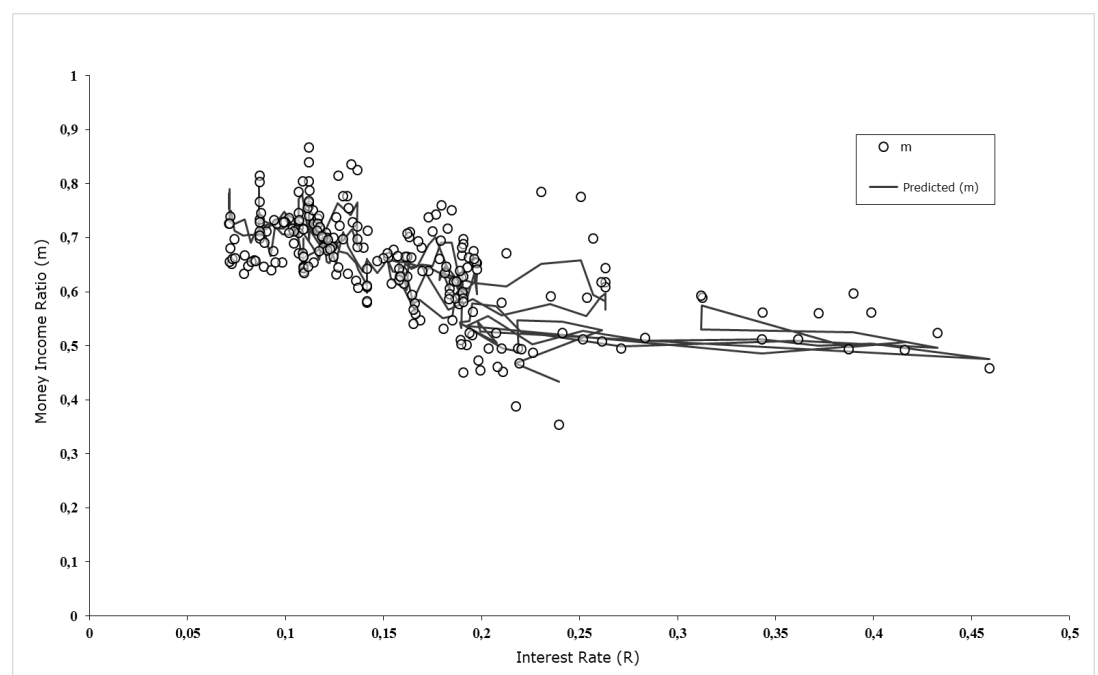

Figure 7: Money Demand Function - Kalman Filter

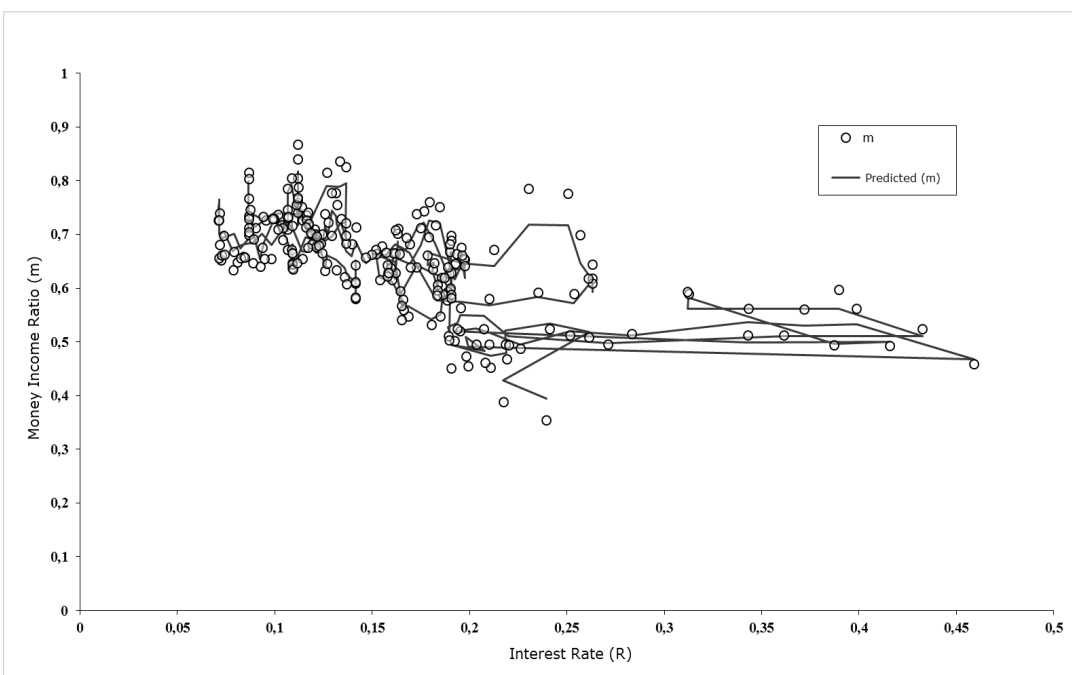


Figure 8: Real vs Expected Demand for Money - Time-Invariant Method

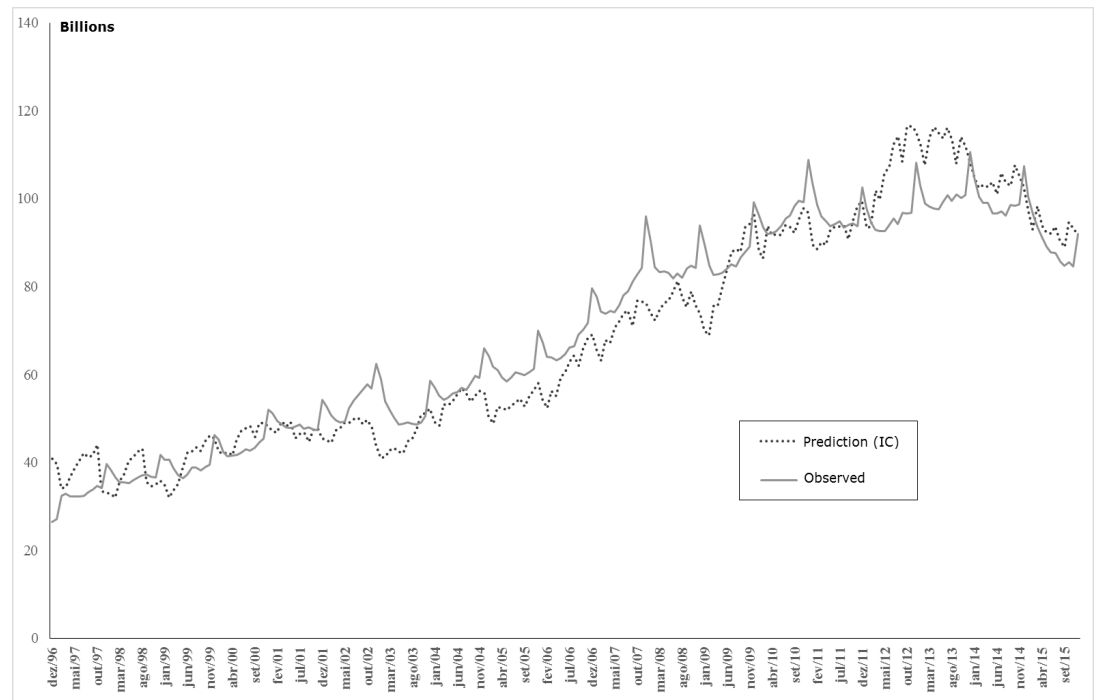

Figure 9: Real vs Expected Demand for Money - Time-Varying Cointegration

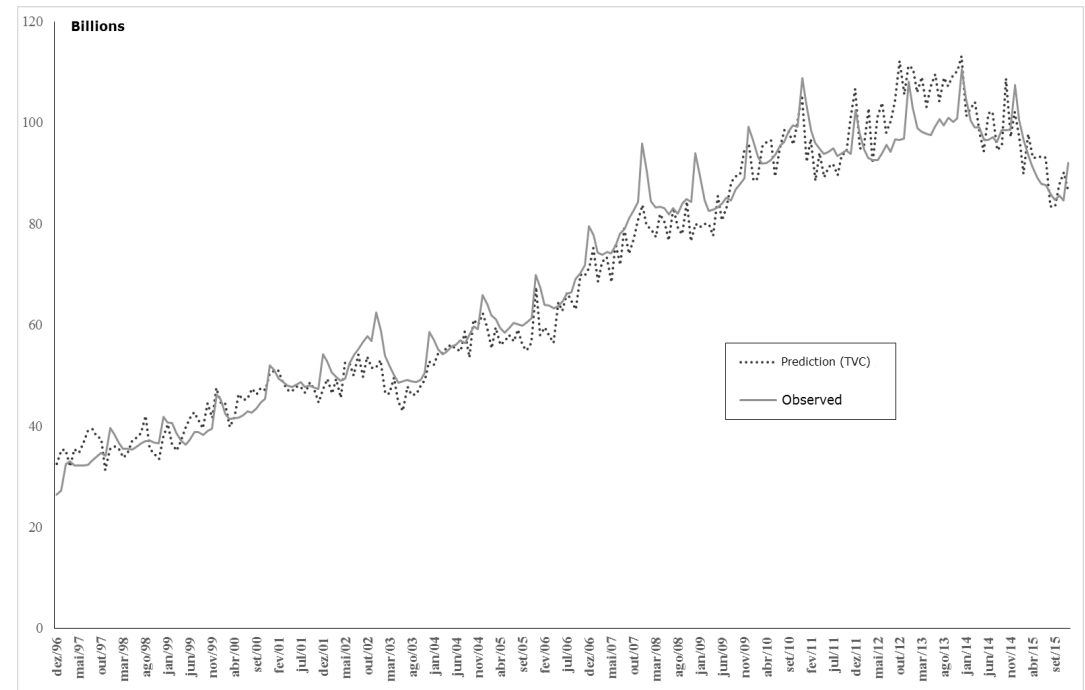


Figure 10: Real vs Expected Demand for Money - Kalman Filter

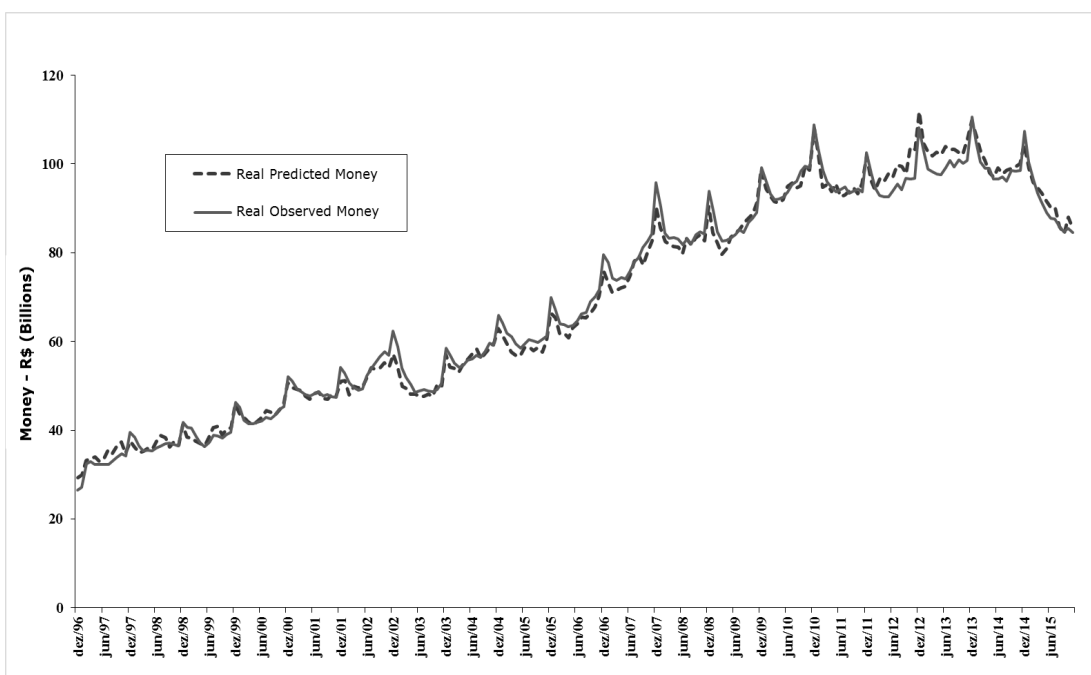

Table 1: RMSE and MAPE for Estimated Demand for Money

\begin{tabular}{l|c|c|c}
\hline & $\begin{array}{c}\text { Time- } \\
\text { Invariant }\end{array}$ & $\begin{array}{c}\text { Time-Varying } \\
\text { Cointegration }\end{array}$ & $\begin{array}{c}\text { Kalman } \\
\text { Filter }^{*}\end{array}$ \\
\hline RMSE & 13.07 & 7.02 & 2.98 \\
MAPE & $11.16 \%$ & $6.59 \%$ & $2.57 \%$ \\
\hline * We also tried the simplest version of the Kalman Filter \\
(equations (22-23)), and the resulting RMSE and MAPE \\
were 4,15 and 3,91\%, respectively, which shows the \\
importance of the lagged term in the extended form.
\end{tabular}

of this cost, as well as interest rates and inflation in the period, aiming to contextualize the analysis of the cost in terms of the macroeconomic situation. The average estimated cost for the period was $0.24 \%$ of GDP, for an average inflation of $6.63 \%$.

We also calculated cost estimates for constant inflation of 10\% (approximate inflation rate in Brazil at the time of writing) and 4.5\% (target set by the Central Bank), considering the average elasticity for the period. The evolution of these costs is illustrated in Figure 12.

In the model with fixed coefficients, the welfare cost of inflation usually moves pari passu with the interest rate observed. In the model with variable coefficients, as in the case of the Kalman filter, the interest-elasticity of demand for money can also respond to interest rates, in which case an apparent positive correlation between interest and welfare cost is not necessarily observed. In particular, higher interest rates may be associated with lower sensitivity of the demand for money to this variable. In this case, the welfare cost 
Figure 11: Evolution of the Welfare Cost in the Period of Jan/1996 to Dec/2015

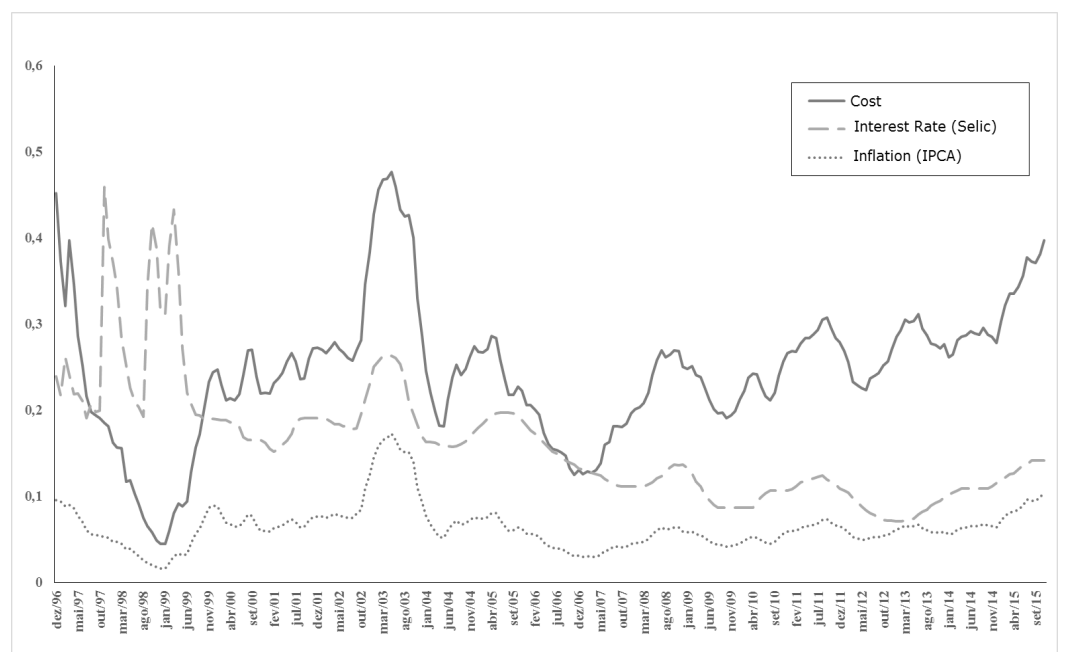

Figure 12: Welfare Costs for Observed, 4.5\% and 10\% Inflation

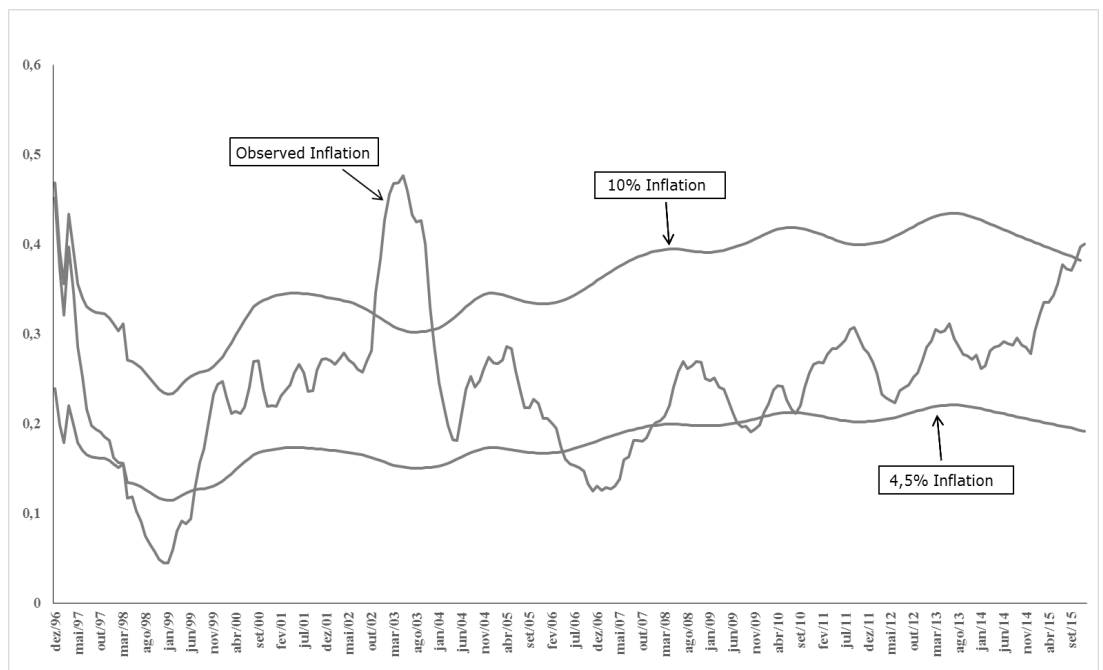


may follow a path less correlated with the interest rate.

Under the hypothesis of constant inflation, using the average elasticity, we come to a cost of $0.35 \%$ of GDP for inflation of $10 \%$ per year, and $0.18 \%$ of GDP for annual inflation of $4.5 \%$.

The welfare cost, in its turn, has a strong and positive correlation with the inflation rate, as we can see in Figure 13.

Figure 13: Correlation Between Welfare Cost and Inflation Rate

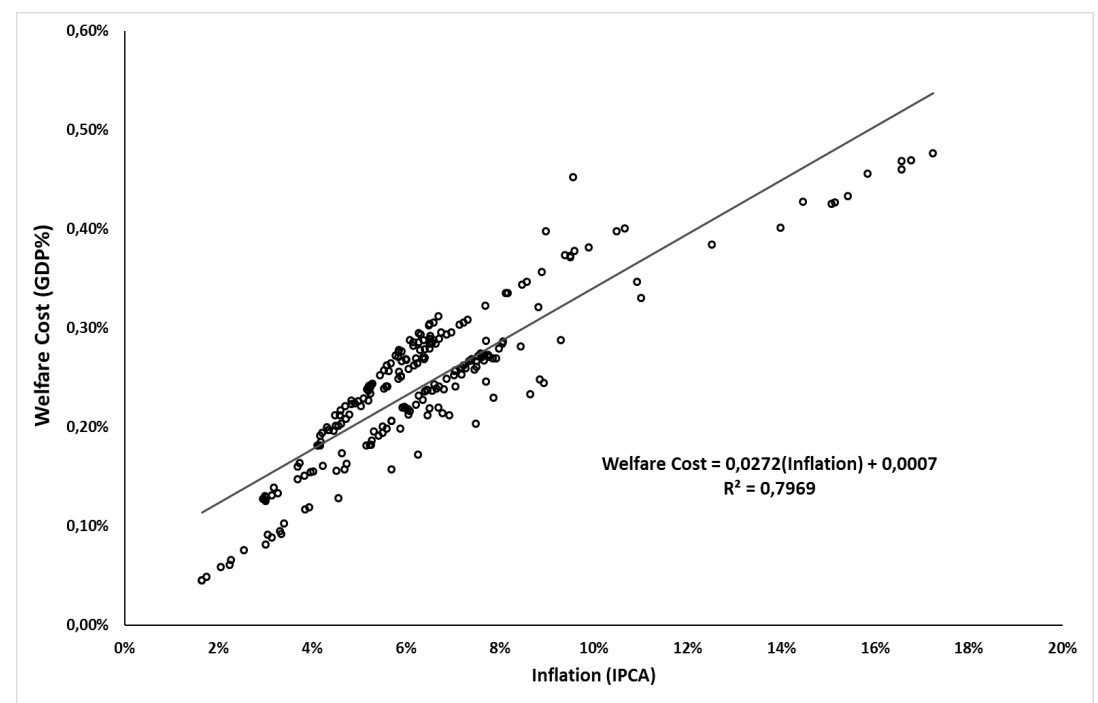

\section{Discussion}

Kumar (2014) concluded that Cagan's model is more adequate to the Indian economy, our results show that Meltzer's model is a better fit for Brazil in the time period under study, as Caetano et al. (2014) also did.

Looking at the latter's results, we can see that our single model captures the same results for the welfare cost of inflation as its multiple econometric specifications. Figure 14 shows that the minimum and maximum costs estimated by the authors correspond roughly to the lowest and highest values, respectively, obtained by this work. Since we let the interest-elasticity vary over time, however, our estimation shows how the cost varies monthly, while Caetano et al. (2014) could only estimate mean values for the entire period. For the inflation rate of $4.5 \%$, the authors estimate welfare costs ranging from $0.15 \%$ to $0.20 \%$. Therefore, the mean cost of $0.18 \%$ estimated by Kalman Filter, presented previously, is inside this range.

The elasticity estimations, however, differ greatly between the two works. As we can see in Figure 15, most of the values from our model lie below the lowest estimate of 0.423 from Caetano et al. (2014), for both the Kalman filter and the time varying cointegration methods. 
Figure 14: Welfare Costs Comparison

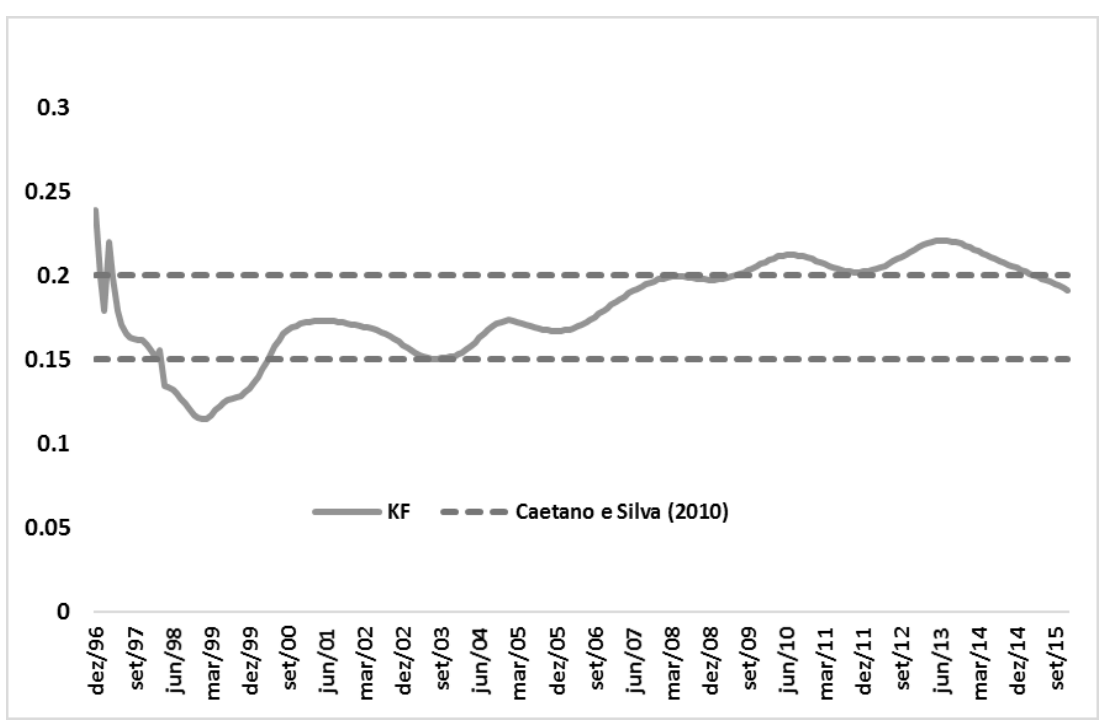

Figure 15: Elasticities Comparison

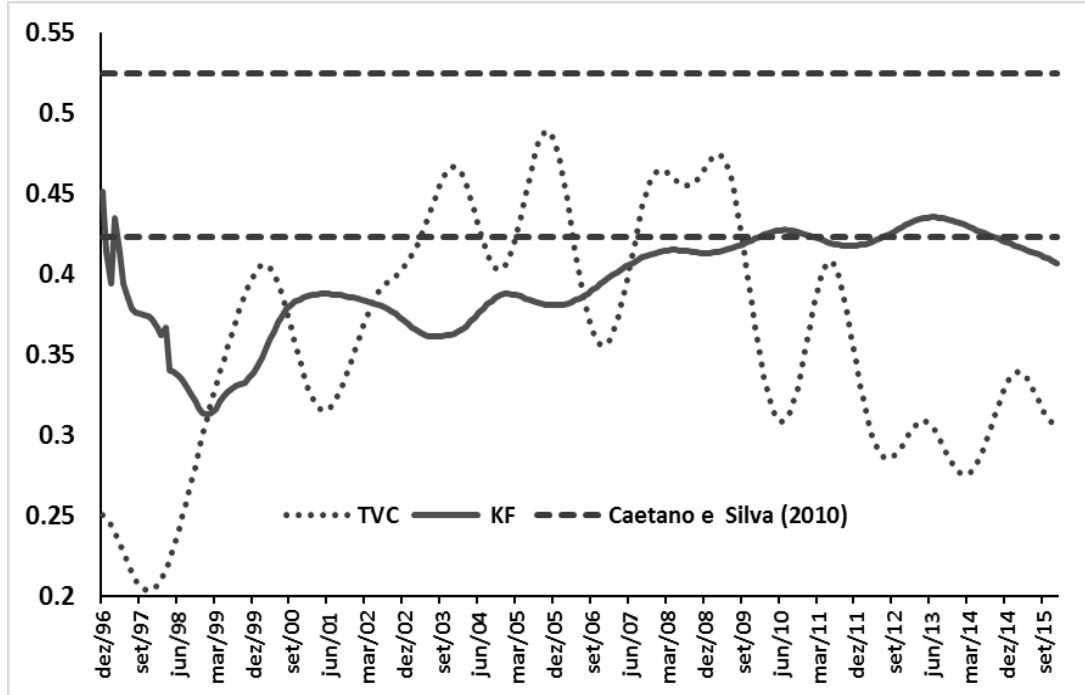




\section{Conclusions}

This study applied two methods to estimate the interest-elasticity of demand for money in Brazil between 1996 and 2015, considering that this parameter can vary over time: time-variant cointegration and Kalman filtering. From the results obtained, monthly estimates of the welfare cost of inflation were calculated. Sufficient variability of elasticities and estimated cost over the period illustrate the limitation of methods that consider invariant parameters.

Likelihood-ratio tests based on bootstrap led to evidence of time-varying cointegration between demand for money and interest rates (in logarithm), supporting the application of this method to estimate elasticities. However, the Kalman filtering estimates proved to be more stable and consistent with the behavior of the Brazilian economy in the period, and demonstrated statistically superior performance.

The average welfare cost of inflation estimated for Brazil in the period from 1996 to 2015 was $0.24 \%$ of GDP, for an average inflation of $6.63 \%$ in this period. Considering constant inflation rates and the average elasticity estimated for the period, we arrived at a cost of $0.35 \%$ of GDP for an inflation rate of $10 \%$ per year, and $0.18 \%$ of GDP for an annual inflation of $4.5 \%$.

\section{References}

Bailey, M. J. (1956), 'The welfare cost of inflationary finance', Journal of Political Economy 64, 93-110.

Barigozzi, M. \& Conti, A. (2014), 'On the Sources of Euro Area Money Demand Stability: A Time Varying Cointegration Analysis', Working Paper.

Bierens, H. J. \& Martins, L. F. (2010), 'Time-varying cointegration', Econometric Theory 26(5), 1453-1490.

Caetano, S. M., Silva Júnior, G. E. \& de Castro Souza Júnior, J. R. (2014), 'Custos de bem-estar da inflação no brasil pós-real', Economia Aplicada 18(2), 271-293.

Cagan, P. (1956), 'The monetary dynamics of hyperinflation', in: M. friedman, ed.', Studies in the quantity theory of money. Chicago: University of Chicago Press pp. 25-117.

Canêdo-Pinheiro, M. (2011), 'Modelo de Cagan e quebras estruturais: evidências para o Crasil (1970-94)', Economia Aplicada 15(2), 151-176.

Choi, I. \& Saikkonen, P. (2004), 'Testing linearity in cointegrating smooth transition regressions', The Econometrics Journal 7(2), 341-365.

Granger, C. W. (1987), 'Developments in the study of cointegrated economic variables', Oxford Bulletin of Economics and Statistics 48, 213-218.

Hall, S. G., Psaradakis, Z. \& Sola, M. (1997), 'Cointegration and Changes in Regime: The Japanese Consumption Function', Journal of Applied Econometrics $12,151-168$. 
Hamming, R. W. (1973), 'Numerical Methods for Scientists and Engineers'.

Hansen, P. R. (2003), 'Structural changes in the cointegrated vector autoregressive model', Journal of Econometrics 114(2), 261-295.

Harvey, A. C. (1989), 'Forecasting, Structural Time Series Models and the kalman Filter'.

Ireland, P. N. (2009), 'On the welfare cost of inflation and the recent behavior of money demand', American Economic Review 99(3), 1040-1052.

Johansen, S. (1988), 'Statistical analysis of cointegration vectors', Journal of Economic Dynamics and Control 12(2-3), 231-254.

Kalman, R. E. (1960), 'A new approach to linear filtering and prediction problems', Journal of Basic Engineering 82(1), 35-45.

Kalman, R. E. \& Bucy, R. S. (1961), 'New results in linear filtering and prediction theory', Journal of Basic Enginnering 93(1), 85-108.

Kumar, S. (2014), 'The Varying Interest Elasticity and the Cost of Inflation in India', Applied Economics Letters 21(7), 497-500.

Lucas Jr., R. E. (2000), 'Inflation and welfare', Econometrica 68(2), 247-274.

Lütkepohl, H., Teräsvirta, T. \& Wolters, J. (1999), 'Investigating Stability and Linearity of a German M1 Money Demand Function', Journal of Applied Econometrics 14(5), 511-525.

Martins, L. F. (2018), 'Bootstrap tests for time varying cointegration', Econometric Reviews 37(5), 466-483.

Meltzer, A. H. (1963a), 'The demand for money: A cross-section study of business firms', Quartely Journal of Economics 77(3), 405-422.

Meltzer, A. H. (1963b), 'The demand for money: The evidence from the time series', Journal of Political Economy 71(3), 219-246.

Miller, S. M., Martins, L. F. \& Gupta, R. (2014), 'A Time-Varying Approach of the US Welfare Cost of Inflation', Macroeconomic Dynamics 23(2), 775-797.

Park, J. Y. \& Hanh, S. B. (1999), 'Cointegrating regressions with time varying coefficients', Econometric Theory 15(5), 664-703.

Penha Cysne, R. (2009), 'Bailey's measure of welfare cost of inflation as a general equilibrium measure', Journal of Money, Credit and Banking 41(2), 451459.

Penha Cysne, R. \& Issler, J. V. (1993), 'Prevendo demanda por moeda com dados mensais', Anais do Encontro Brasileiro de Econometria .

Serletis, A. \& Yavari, K. (2004), 'The welfare cost of inflation in Canada and the United States', Economics Letters 84(2), 199-204.

Sidrauski, M. (1967), 'Inflation and economic growth', Journal of Political Economy 75(6), 796-810. 
Teräsvirta, T. \& Eliasson, A. (2001), 'Non-linear error correction and the UK demand for broad money, 1878-1993', Journal of Applied Econometrics 16(3), 277-288.

Zuo, H. \& Park, S. Y. (2011), 'Money Demand in China and Time-Varying Cointegration', China Economic Review 22(3), 330-343. 
